\title{
Peroral cholangioscopy: use of a Roth Net retriever for difficult biliary stones
}

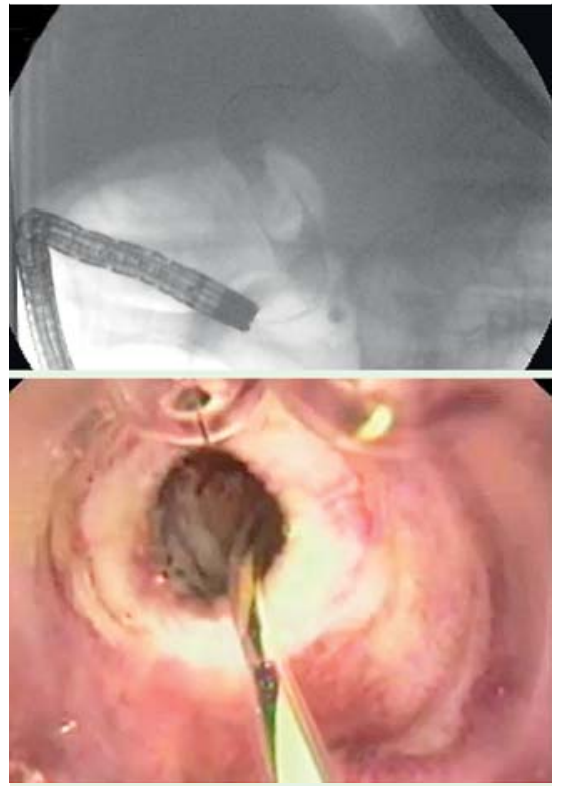

Fig. 1 Cholangiography showing a large stone in the common bile duct. Sphincteroplasty was performed using a large balloon, dilating the otomy.

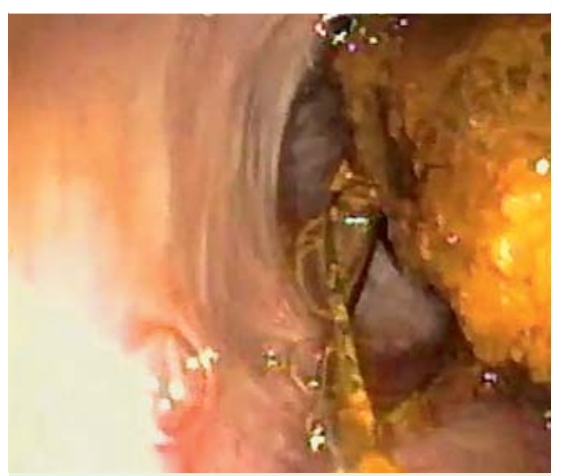

Fig. 2 The largest stone could not be removed using a basket because of its size and position.

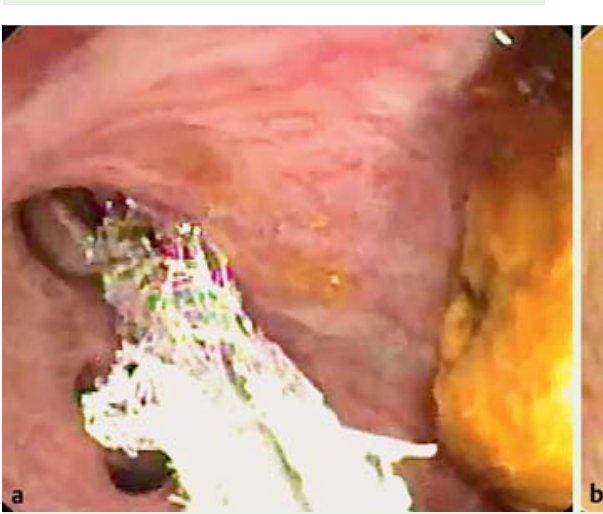
sphincter to $17 \mathrm{~mm}$, without prior sphincter-
Bile duct stones are routinely removed during endoscopic retrograde cholangiopancreatography (ERCP) with biliary sphincterotomy, using standard balloon or basket extraction techniques. However, in approximately $10 \%-15 \%$ of patients, bile duct stones may be difficult to remove owing to challenging access to the bile duct, large bile duct stones $(>15 \mathrm{~mm}$ in diameter), intrahepatic stones, or impacted stones in the bile duct [1-3]. In such cases, an alternative procedure to ensure biliary drainage may be warranted.

A 65-year-old man was admitted for acute cholangitis with multiple organ dysfunction. Upper abdominal ultrasound showed a dilated common bile duct (CBD, $17 \mathrm{~mm}$ ), containing multiple stones.

After hemodynamic stabilization and the initiation of antibiotic therapy, the patient underwent emergency ERCP. A pyloric and duodenal bulb deformation was noted, which prevented stabilization of the duodenoscope after CBD cannulation. Sphincteroplasty was performed using a large balloon, dilating the sphincter to $17 \mathrm{~mm}$ (๑ Fig.1), without prior sphincterotomy. A pediatric colonoscope was then advanced slowly into the CBD over a catheter, allowing its entry into the biliary tract. Multiple biliary stones were seen under direct visualization, the largest of which was $16 \mathrm{~mm}$.

The largest stone could not be removed using a basket because of its size and position ( Fig. 2). Therefore, a Roth Net (US Endoscopy, Mentor, Ohio, USA) retriever was used. Under direct visualization, the

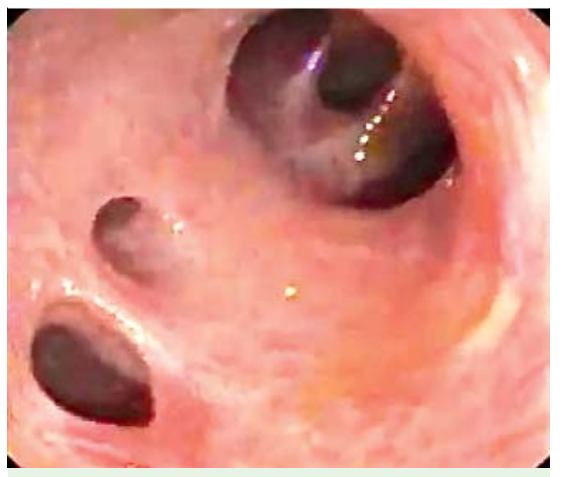

Fig. 4 After the procedure, complete stone removal was confirmed by direct visualization.

Roth Net was opened, and easily captured the largest stone, which was removed without fragmentation ( Fig.3a,b,c). The remaining small biliary stones and sludge were removed using a balloon. After the procedure, complete stone removal was confirmed by direct visualization ( Fig.4). The procedure was performed using carbon dioxide insufflation. The patient was discharged 1 week later. Peroral cholangioscopy allows therapeutic procedures in the biliary tract under direct visualization [4]. In the present case, a novel retrieval method, which used an accessory that is widely available, was used to remove a difficult bile duct stone.

\section{Endoscopy_UCTN_Code_TTT_1AR_2AH}

\section{Competing interests: None}

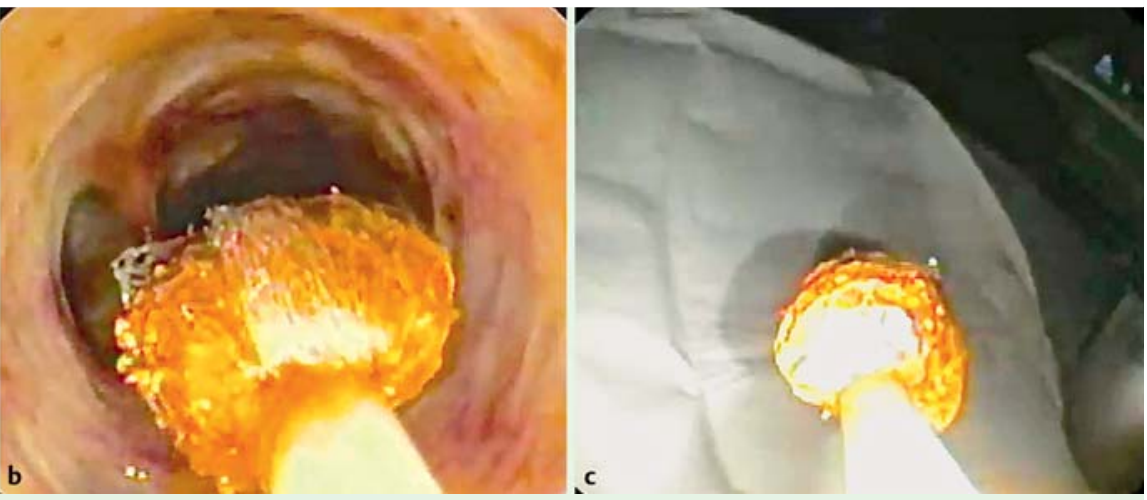

Fig. 3 Retrieval of the bile duct stone using a Roth Net (US Endoscopy, Mentor, Ohio, USA). a Under direct visualization, the Roth Net was opened. b The net captured the largest stone easily. $\mathbf{c}$ The stone was removed without fragmentation. 


\section{Vera Costa Santos, Nuno Nunes, Filipa Ávila, Ana Catarina Rego, José Renato Pereira, Nuno Paz, Maria Antónia Duarte}

Department of Gastroenterology, Hospital do Divino Espírito Santo, Ponta Delgada, Portugal

\section{References}

1 Trikudanathan G, Navaneethan U, Parsi MA. Endoscopic management of difficult common bile duct stones. World J Gastroenterol 2013; 19: 165 - 173

2 Strömberg C, Nilsson M. Nationwide study of the treatment of common bile duct stones in Sweden between 1965 and 2009. Br J Surg 2011; 98: 1766 - 1774

3 Cairns SR, Dias L, Cotton PB et al. Additional endoscopic procedures instead of urgent surgery for retained common bile duct stones. Gut 1989; 30: 535-540

4 Ghersi S, Fuccio L, Bassi M et al. Current status of peroral cholangioscopy in biliary tract diseases. World J Gastrointest Endosc 2015; 7: $510-517$
Bibliography

DOI http://dx.doi.org/

10.1055/s-0042-102958

Endoscopy 2016; 48: E95-E96

(c) Georg Thieme Verlag KC

Stuttgart · New York

ISSN 0013-726X

\section{Corresponding author}

Vera Costa Santos, MD

Department of Gastroenterology Hospital do Divino Espírito Santo Rua Professor Alfredo Bensaude $n^{\circ} 10,1^{\circ}$ direito 9500-700, Ponta Delgada Portugal vera@multi.pt veracostsantos@gmail.com 